ORIGINAL ARTICLE

\title{
The effectiveness of ergonomic interventions on return-to- work after low back pain; a prospective two year cohort study in six countries on low back pain patients sicklisted for 3-4 months
}

\author{
J R Anema, B Cuelenaere, A J van der Beek, D L Knol, H C W de Vet, W van Mechelen
}

Occup Environ Med 2004;61:289-294. doi: 10.1136/oem.2002.006460

See end of article for authors' affiliations

Correspondence to: Dr J R Anema, Occupational Physician Body@Work, TNO-VU

University Medical Centre, Van der Boechorststraat 7, 1081 BT Amsterdam, Netherlands: h.anema@vumc.nl

\begin{abstract}
Aims: To study occurrence and effectiveness of ergonomic interventions on return-to-work applied for workers with low back pain (LBP).

Methods: A multinational cohort of 1631 workers fully sicklisted 3-4 months due to LBP (ICD-9 codes 721 , $722,724)$ was recruited from sickness benefit claimants databases in Denmark, Germany, Israel, Sweden, the Netherlands, and the United States. Medical, ergonomic, and other interventions, working status, and return-to-work were measured using questionnaires and interviews at three months, one and two years after the start of sickleave. Main outcome measure was time to return-to-work. Cox's proportional hazards model was used to calculate hazard ratios regarding the time to return-to-work, adjusted for prognostic factors.

Results: Ergonomic interventions varied considerably in occurrence between the national cohorts: $23.4 \%$ (mean) of the participants reported adaptation of the workplace, ranging from $15.0 \%$ to $30.5 \%$. Adaptation of job tasks and adaptation of working hours was applied for $44.8 \%$ (range $41.0-59.2 \%$ ) and $46.0 \%$ (range 19.9-62.9\%) of the participants, respectively. Adaptation of the workplace was effective on return-to-work rate with an adjusted hazard ratio (HR) of $1.47(95 \% \mathrm{Cl} 1.25$ to $1.72 ; \mathrm{p}<0.0001)$. Adaptation of job tasks and adaptation of working hours were effective on return-to-work after a period of more than 200 days of sickleave with an adjusted HR of $1.78(95 \% \mathrm{Cl} 1.42$ to $2.23 ; \mathrm{p}<0.0001)$ and $1.41(95 \% \mathrm{Cl} 1.13$ to $1.76 ; p=0.002)$, respectively.

Conclusions: Results suggest that ergonomic interventions are effective on return-to-work of workers long term sicklisted due to LBP.
\end{abstract}

O ccupational disability due to low back pain (LBP) is a multifactorial problem. ${ }^{12}$ Many studies suggest that individual factors as well as work related factors are predictive for return-to-work after sickleave due to LBP. . $^{3-9}$ In two recent reviews a lack of modified work is mentioned as a risk factor for long-term disability. ${ }^{2}{ }^{10}$ Although work related factors are predictive for return-to-work, to date most studies evaluated the effectiveness of medical interventions directed to the individual and not directed to the work environment. ${ }^{11}{ }^{12}$ The review by Krause and colleagues ${ }^{13}$ suggested that ergonomic interventions might be effective in the occupational rehabilitation of sicklisted workers. However, there is little evidence about the effectiveness of these interventions on return-to-work. Staal and colleagues ${ }^{11}$ recently concluded in their review that ergonomic interventions for the return-to-work of patients sicklisted due to LBP were only included in three randomised controlled trials (RCTs). ${ }^{14-16}$ One of these studies ${ }^{14}$ even suggested that ergonomic interventions are more effective on return-towork than clinical interventions.

Sickleave and disability due to LBP is a common, crossnational problem. Because the disability rates and costs due to long term sickleave are increasing in many industrialised countries, the International Social Security Association (ISSA) initiated a multinational study to identify successful medical, ergonomic, and social security interventions for the return-to-work of workers long term sicklisted due to LBP. ${ }^{17}$ Hanson et al reported that medical interventions in this multinational cohort study were not effective on return-towork. $^{18}$
The objective of our study was to study the occurrence and effectiveness of different kinds of ergonomic interventions on return-to-work within two years after the first day of sickleave. The study population comprised a multinational cohort with workers from six countries who are sicklisted for 3-4 months due to LBP. The central question was: "Do workers with ergonomic interventions show earlier return-towork for a long lasting period than workers without these interventions?"

\section{METHODS}

\section{Study design}

This prospective two year cohort study comprised six cohorts of workers sicklisted due to LBP in Denmark, Germany, Israel, the Netherlands, Sweden, and the USA. Because the study had a core design comprising several basic features, ${ }^{8}{ }^{17-19}$ it was possible to integrate the national datasets to a homogeneous internationally standardised dataset for crossnational analysis. ${ }^{20}$

\section{Cohort recruitment and data collection}

A consecutive series of 2825 workers fully sicklisted 3-4 months because of LBP (ICD-9 codes 721, 722, 724) were recruited in the period May 1995 to September 1996, through databases of sickness benefit claimants in the participating countries. ${ }^{17}$ These workers were asked to participate and to sign a letter of authorisation, permitting their data to be used for the cohort study. At 3-4 months (baseline), and one (T2) and two years (T3) after the first day of sickleave, data were collected using questionnaires and 
Main messages

- Many studies have evaluated the effectiveness of medical interventions on return-to-work of workers sicklisted due to low back pain.

- To date few studies have evaluated the occurrence and effectiveness of ergonomic interventions for the occupational rehabilitation of workers with low back pain.

- This multinational prospective cohort study suggests that ergonomic interventions are frequently applied for the occupational rehabilitation of long term sicklisted workers, although there is substantial variation in occurrence and type of intervention, between countries.

- Workplace adaptations, and, on the long term, adaptation of job tasks and working hours seem to be effective to improve return-to-work for workers sicklisted for 3-4 months due to low back pain.

interviews. ${ }^{18}$ The response rates at $\mathrm{T} 2$ and $\mathrm{T} 3$ were $85 \%$ and $77 \%$, respectively. Non-response analysis showed that there were no major differences between the response group and the non-response group with regard to demographic characteristics. $^{18}$

Because most ergonomic interventions could not be provided unless the worker returned to work, we studied the sample $(n=1631)$ comprising participants who have ever resumed work-for a long or short period-in the two years after the first day of sickleave. Of these participants 30-33\% had missing data (on sickleave duration, work status, ergonomic interventions, and confounding factors) in multivariate analyses. The multivariate samples concerning the studied ergonomic interventions had similar demographic, work, and back pain characteristics (age, gender, pain intensity, sciatica, Hannover ADL, and working hours) to the samples of the participants with missing data, except for gender $(57.2-57.8 \% \vee 46.6-47.4 \%$ male) and sciatica (73.2$73.4 \%$ v 66.6-67.2\%). However, both gender and sciatica were not identified as confounders in the multivariate analyses.

\section{Interventions}

\section{Ergonomic interventions}

Ergonomic interventions were selected based on two principles: the ergonomic intervention should be applied in every participating country; and the ergonomic intervention should be applied as a stand-alone. The following three ergonomic interventions were identified: workplace adaptation, adaptation of job tasks, and adaptation of working hours. Each ergonomic intervention was measured as a dichotomous variable: it was applied or not. ${ }^{20}$ Pearson correlation coefficients between all ergonomic interventions were calculated and used to identify to what extent different ergonomic interventions coincided. All Pearson correlation coefficients of combinations of the selected ergonomic interventions were less than 0.4. Therefore, we examined them separately. Table 1 clarifies the three ergonomic interventions.

\section{Outcomes}

\section{Return-to-work}

Two outcome measures were collected in the international database: date of first return-to-work; and working status at T2 and T3. Unfortunately, no information was available about the duration of the initial work resumption. For this reason, return-to-work was defined as "long lasting" if a worker was still working at T3. Based on this definition the

\section{Policy implications}

- Interventions for the occupational rehabilitation of workers sicklisted due to LBP should include ergonomic interventions.

- Most of the ergonomic interventions in this study seem to reveal effects on long term return-to-work; the impact on the prevention of occupational disability due to LBP and on the reduction of costs to society may be important.

- The effectiveness of ergonomic interventions on returnto-work should be confirmed in future randomised controlled trials.

following dependent variable was calculated: the number of days from first day of sickleave until first date of work resumption resulting in long lasting return-to-work. Thus for workers who did not work any more at T3, time to return-towork was censored at T3 in Cox regression analyses.

\section{Potential confounders}

Several demographic, health related, and work related baseline characteristics were derived from the international database $\mathrm{e}^{20}$ and tested as potential confounding factors. It was decided to select only potential confounders, which were measured in all participating countries. Before we adjusted for confounding, the effect of each ergonomic intervention was corrected for the effect of other ergonomic interventions. Table 2 presents an overview of all potential confounders, adjusted for in multivariate analysis. For detailed information about the content and categorisation of these variables we refer to the technical guide of the International Database. $^{20}$

\section{Statistical analysis}

Univariate analyses

A Kaplan-Meier survival curve was estimated to describe the univariate relations between ergonomic interventions and time until first return-to-work. Differences were tested using the log rank test.

\section{Multivariate analyses}

When the Kaplan-Meier analysis showed that Cox's proportional hazards assumption was met, Cox's proportional hazards analysis was used to describe the multivariate associations between each ergonomic intervention and the time to first return-to-work. All potential prognostic factors were checked for confounding. All potential confounders were manually and separately entered into the multiple regression model. A prognostic factor was defined as a

Table 1 Definitions of workplace interventions

Workplace adaptation

The realisation of adaptations in workplace including any technical aids, such as a different chair or desk/table, special tools, a lifting aid, an adapted transport during work, etc

Adaptation in working hours

Changes in number and/or pattern of working hours: different shifts, less or more hours ("partial work resumption"), more variation in hours, etc

Adaptation of job tasks

Change of job tasks, including minor changes such as not having to carry things 
Table 2 Listing of potential confounders and effect modifiers, adjusted for in multiple regression analysis

\section{Demographic and patient related characteristics}

Gender, country, age, education, and Quetelet Index

\section{Work related interventions and characteristics}

Other ergonomic interventions (adaptation workplace, job tasks adaptation, working hours adaptation, therapeutic work resumption, job training, sheltered workshop)

Patient working hours, patient job duration, firm company size, patient work ability, attitude towards work, physical job demands, social support, job strain (Karasek Theorell's demand-support-control scale)

\section{Health related characteristics}

General health (subscale of SF-36), active coping, passive coping, co-morbidity (interference with work resumption), pain intensity (von Korff pain intensity scale), pain sciatica, sickleave history due to back pain (in the last year), patient functional limitations (Hannover ADL)

\section{Medical interventions}

Surgery, pain medication, passive treatment, manipulation, active treatment (individual or groupwise training, gymnastics, back school)

confounder if the regression coefficient of the outcome measure changed more than $10 \%$ when the factor was entered to the model. When a confounder was identified, this confounder was added to the model; this procedure was repeated until there was not more than $10 \%$ change of the regression coefficient. Analyses were performed using the SPSS 10.0 software package (SPSS Inc., Illinois, USA). A prognostic factor was defined as an effect modifier when it had a significant interaction with the intervention at a significance level of $\mathrm{p}<0.05$.

\section{RESULTS}

\section{Baseline characteristics and return-to-work}

Table 3 presents the baseline characteristics of 1631 participants in the selected cohort. These workers all returned to work for at least a short period during follow up. A total of 1179 of 1631 workers $(72.3 \%)$ were still working at T3 (that is, two years after the first day of sickleave).

\section{Occurrence and timing of ergonomic interventions}

As fig 1 shows, the occurrence of different types of ergonomic interventions varied substantially between the national cohorts. All frequencies presented have been calculated for workers who have resumed their work at least for a short period. Ergonomic interventions were more often applied in the cohorts in Israel, the Netherlands, Denmark, and the USA than in the Swedish and German cohorts.

Adaptation of the workplace was done for $23.4 \%$ (mean) of the workers in all cohorts during two years after the first day

Table 3 Baseline characteristics of the cohort of participants sicklisted for $3-4$ months $(n=1631$ )

\begin{tabular}{ll}
\hline Baseline characteristics & Cohort $(\mathbf{n}=1631)$ \\
\hline Patient characteristics & \\
$\quad$ Mean (SD) age (years) & $41.1(9.9)$ \\
Gender (\% male) & 54.3 \\
Low back pain related characteristics & 71.5 \\
$\quad$ Sciatica (\%) & 56.8 \\
$\quad$ History of sickleave due to LBP in the past & \\
year (\%) & $5.5(2.4)$ \\
Mean (SD) pain intensity (Von Korff) & $51.6(23.6)$ \\
Mean functional limitations (Hannover ADL; & \\
O-100) & \\
Work related characteristics & $40.0(10.9)$ \\
Mean (SD) working hours (h) & $3.20(0.57)$ \\
Mean (SD) social support (Karasek; 1-4) & $1.87(0.69)$ \\
$\quad$ Mean (SD) physical job demands & $1.06(0.41)$ \\
(Karasek; $1-4)$ & \\
Mean (SD) job strain (Karasek; 0.25-4) &
\end{tabular}

of sickleave, ranging from $15.0 \%$ in the German cohort to $30.5 \%$ in the Dutch cohort. Adaptation of job tasks was reported by $44.8 \%$ (mean) of the workers (range $41.0 \%$ in the American to $59.2 \%$ in the Danish cohort). Adaptation of working hours was done for $46.0 \%$ (mean) of the workers, with a range of $19.9-62.9 \%$ in the German and Dutch cohort, respectively. Combinations of ergonomic interventions occurred to a variable degree in the six cohorts. The most common combination was adaptation of job tasks and adaptation of working hours: $2 \%$ and $14 \%$ of the cases in the German and Swedish cohorts, respectively; $30-35 \%$ in the Danish, Dutch, and American cohorts; and up to 52\% of the cases in the Israeli cohort. Other combinations of two or three ergonomic interventions were relatively infrequent: they occurred in less than $17 \%$ of the working respondents in all cohorts. The exception was the Dutch cohort, in which two or three different types of ergonomic interventions coincided in up to $33 \%$ of the working respondents. ${ }^{17}$

According to the respondents, almost all ergonomic interventions were applied during the first year after the start of sickleave. The application of ergonomic interventions was not measured in relation to the timing of work resumption. Ergonomic interventions could be applied before, during, and/or after work resumption. Workplace adaptation, when applied in the first year, occurred around the sixth month of sickleave in all participating countries. Adaptation of job tasks was reported in the first year, ranging from six months in the Netherlands to nine months in the US cohort. Adaptation of working hours was applied between six months in the Dutch cohort and 10 months in the USA.

\section{Effectiveness of ergonomic interventions Adaptation of the workplace}

In the Kaplan-Meier analysis, the survival curves for workers who received workplace adaptation and those who did not, differed significantly (log rank test; $p<0.0001$ ) (see fig 2 ). In the Kaplan-Meier analysis, the median duration of absence from work in the group with workplace adaptation was 206 days compared to 311 days for the group without this intervention. In the Cox regression analysis $(\mathrm{n}=1133)$ the adjusted hazard ratio (HR) of the return-to-work rates was 1.47 (95\% confidence interval 1.25 to $1.72 ; p<0.0001$ ) in favour of workers with a workplace adaptation. The results of these analyses, as well as the prognostic factors adjusted for in the final multivariate model, are presented in table 4 . No significant interaction with the intervention was found.

\section{Adaptation of job tasks}

Based on the Kaplan-Meier analysis, the survival curves for workers who received the adaptation of job tasks and those who did not, did not differ significantly (log rank test; 


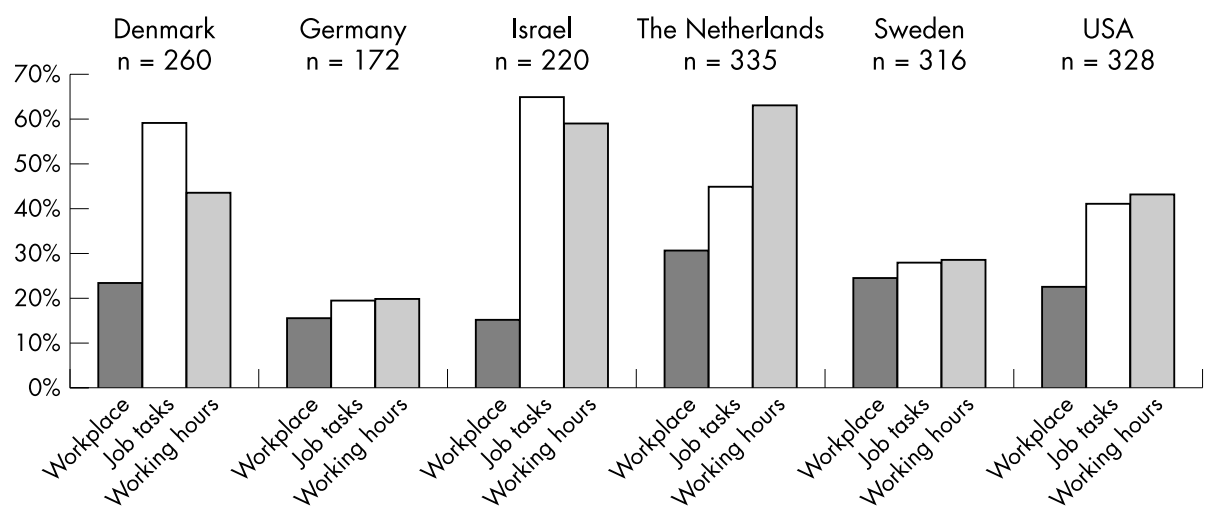

Figure 1 Ergonomic interventions in six participating countries applied for \% of respondents $(n=1631)$ who were sicklisted 3-4 months due to low back pain and returned to work during the first two years after the start of sickleave.

$\mathrm{p}=0.26$ ). The median duration of absence from work for workers with adaptation of job tasks was 299 days compared to 244 days for workers without this intervention. The curves are shown in fig 3.

Cox's proportional hazards model $(n=1147)$ was used to calculate adjusted HRs to compare the return-to-work rates of both groups. However, an assumption of Cox's proportional hazards model is that the HR should remain constant over time. This was not the case for this intervention. When looking at the survival curves, two different periods could be distinguished regarding the number of days after the first day of sickleave: until 200 days of sickleave the rate of return-towork seems to be in favour of the non-intervention group, whereas after this period the rate of return-to-work of the intervention group is higher. By means of Cox regression analyses with time dependent covariates, we calculated HRs for workers with 200 and less days of sickleave to the date of first return-to-work and for workers with more than 200 days of sickleave. Table 4 presents the results of the analyses, as well as the prognostic factors adjusted for in the final multivariate model. The hazard ratio was in favour of the group without adaptation of work tasks for workers who returned to work within 200 days of sickleave $(\mathrm{HR}=0.78$; $95 \%$ CI 0.65 to $0.95, \mathrm{p}=0.01$ ). However, for workers who returned to work after 200 days the adjusted hazard ratio was 1.78 in favour of the group with adaptation of job tasks (95\% CI 1.42 to $2.23, \mathrm{p}<0.0001$ ). No significant interaction with the intervention was found.

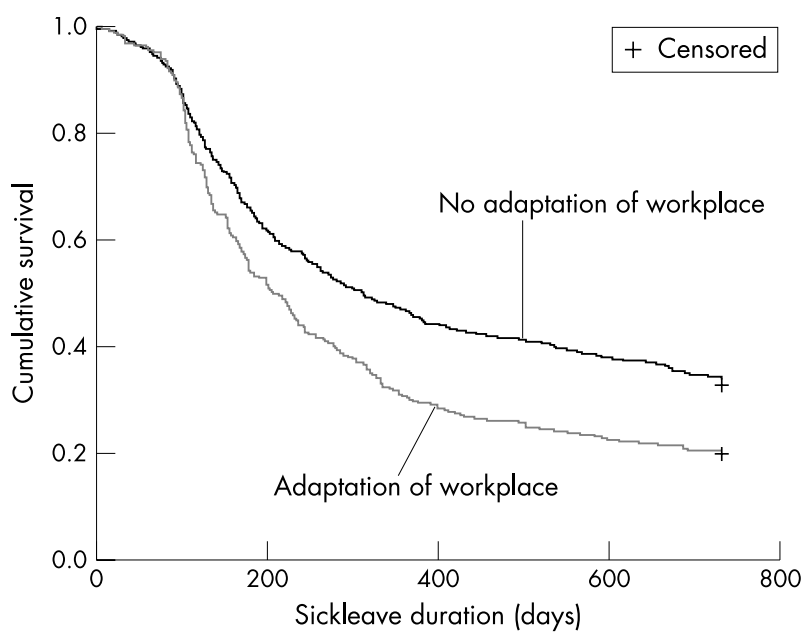

Figure 2 Survival curves of absence from work for workers with and without adaptation of the workplace.

\section{Adaptation of working hours}

The survival curves for workers who received adaptation of working hours and those who did not, differed significantly (Kaplan-Meier analysis; log rank test; $\mathrm{p}=0.02$ ). The median duration of sickleave in the group with adaptation of working hours was 270 days compared to 291 days for the group without this intervention. The curves for both groups are shown in fig 4.

Based on the Kaplan-Meier analysis we calculated in the next step the HRs by means of Cox regression analyses with time dependent covariates, for both the workers with 200 or less days of sickleave and for the workers with more than 200 days of sickleave (table 4). There was no difference in return-to-work rate between the group with and without adaptation of working hours for the workers who returned to work within 200 days of sickleave (HR $=1.14 ; 95 \%$ CI 0.99 to $1.32, \mathrm{p}=0.08)$. However, for the workers who returned to work after 200 days the adjusted HR was 1.41 in favour of the group with adaptation of working hours (95\% CI 1.13 to 1.76 , $\mathrm{p}=0.002$ ). No significant interaction with the intervention was found.

\section{DISCUSSION}

In this paper the two year follow up results are presented of a unique multinational prospective cohort study regarding the effectiveness of ergonomic interventions on return-to-work after sickleave due to LBP. The results indicate that ergonomic interventions have a beneficial effect on returnto-work. Workplace adaptations and, in the long term, adaptation of job tasks and working hours improved return-to-work rate.

\section{Strengths and weaknesses of the study}

A principal strength of this study is that, to our knowledge, this is the first prospective cohort study that describes the occurrence and effectiveness of different types of ergonomic interventions for the occupational rehabilitation of workers sicklisted due to LBP. In contrast to medical interventions, there is little evidence about the effectiveness of ergonomic interventions on return-to-work. Another strength of this study is that an international core design was used in six participating countries and an international standardised dataset was composed. This allowed us to pool the data from a large multinational cohort of workers sicklisted due to LBP and to perform a cross-national analysis. ${ }^{17}{ }^{20}$ Our analyses did not suggest that the effectiveness of these interventions is different in the participating countries. Therefore it has the benefit that the results of this study theoretically are generalisable to all participating countries. 
Table 4 Results of the survival analyses (Kaplan-Meier and multiple Cox regression analyses)

\begin{tabular}{|c|c|c|c|c|c|c|}
\hline & \multicolumn{2}{|c|}{ Median number of days off work } & \multirow[b]{2}{*}{$\begin{array}{l}\text { Log rank test } \\
\text { (p value) }\end{array}$} & \multirow[b]{2}{*}{ Unadjusted HR } & \multicolumn{2}{|c|}{ Adjusted $\mathrm{HRs}$ for return-to-work $(95 \% \mathrm{Cl})$, Cox regression } \\
\hline & Intervention & No intervention & & & $\begin{array}{l}\text { Workers } \leqslant 200 \text { days of } \\
\text { sickleave }\end{array}$ & $\begin{array}{l}\text { Workers }>200 \text { days of } \\
\text { sickleave }\end{array}$ \\
\hline $\begin{array}{l}\text { Adaptation of } \\
\text { workplace }\end{array}$ & 206 & 311 & $<0.0001$ & $1.44(1.24-1.69)$ & \multicolumn{2}{|c|}{$1.47(1.25 \text { to } 1.72)^{*}$} \\
\hline $\begin{array}{l}\text { Adaptation of job } \\
\text { tasks }\end{array}$ & 299 & 244 & 0.26 & $1.09(0.95-1.24)$ & $0.78+(0.65$ to 0.95$)$ & $1.78+(1.42$ to 2.23$)$ \\
\hline $\begin{array}{l}\text { Adaptation of } \\
\text { working hours }\end{array}$ & 270 & 291 & 0.02 & $1.17(1.03-1.35)$ & $1.14 \ddagger(0.99$ to 1.32$)$ & $1.41 \ddagger(1.13$ to 1.76$)$ \\
\hline
\end{tabular}

A limitation of this study is the observational design, which is susceptible to bias and confounding. Firstly, the association between ergonomic interventions and return-towork can be confounded by other variables. For instance, ergonomic interventions could be offered to workers who have more chance to resume work by, for example, a better health status or lesser workload. In this case confounding causes an overestimation of the effectiveness. Therefore, we adjusted for the influence of many potential confounders, such as demographic, medical, and work related characteristics and interventions. However, the possibility that unknown factors confounded the association cannot be ruled out. Therefore, we have to be cautious with the interpretation of the results. They need to be confirmed in an intervention study with a randomised controlled design. A second source of bias is that ergonomic interventions frequently coincide with work resumption. This can cause an overestimation of the effect of ergonomic interventions. Therefore, we included only participants who ever resumed work in the two years after the start of sickleave. A third possible source of bias is recall bias: workers who returned to work long term might assume that an ergonomic intervention contributed to their return-to-work, whereas workers who did not return to work long term might more easily forget that they had received an ergonomic intervention. ${ }^{21}$ This bias could cause an overestimation of the effect. However, recall bias is not likely, because information on ergonomic interventions was requested from the worker with a clear question including

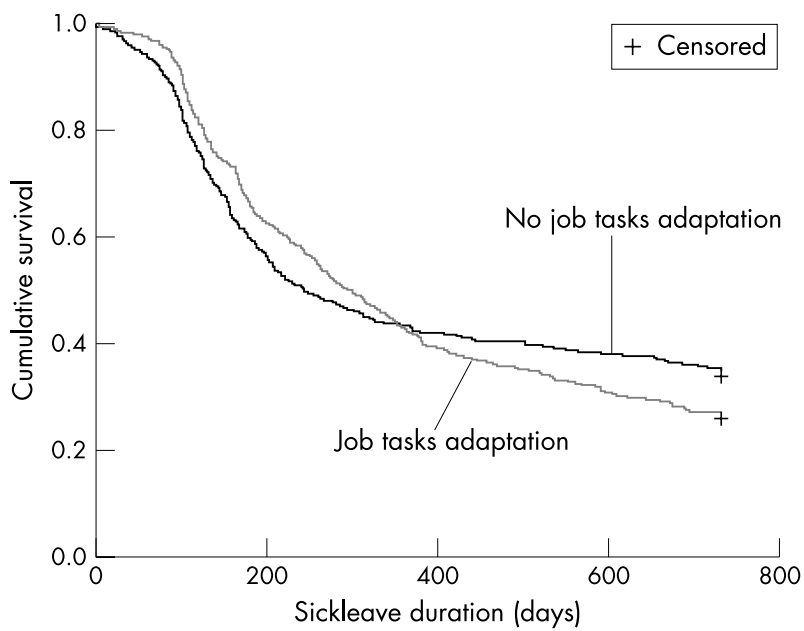

Figure 3 Survival curves of absence from work for workers with and without adaptation of job tasks. several examples. Fourthly, selective omission of data can occur if loss to follow up is related to the outcome measure. For instance, a selective loss to follow up of workers who received an ergonomic intervention and did not return to work long term. In this case the (selection) bias can cause an overestimation of the effect. However, comparison between groups with missing data and the study cohort revealed no major differences except for sciatica and gender. These variables were not identified as confounders in the multivariate analysis.

\section{Comparison with other studies}

Although this study shows that ergonomic interventions are frequently applied as return-to-work interventions in several countries, there are to date few studies with methodologically rigorous designs that investigated the effectiveness of ergonomic interventions on return-to-work of workers with LBP. ${ }^{11}{ }^{12}$ To date Loisel and colleagues ${ }^{14}$ performed the only RCT evaluating the effectiveness of ergonomic interventions on return-to-work. In two other RCTs ${ }^{15}{ }^{16}$ ergonomic interventions were only applied when indicated and were a minor part of a combination of interventions. Both RCTs reported negative results about the effectiveness of their intervention strategy on return-to-work. Loisel and colleagues ${ }^{14}$ found that workers with ergonomic interventions returned 1.9 times faster than those with usual care. This ratio is comparable to the HRs we found in this cohort study. However, the ergonomic interventions in the Loisel et al study were applied

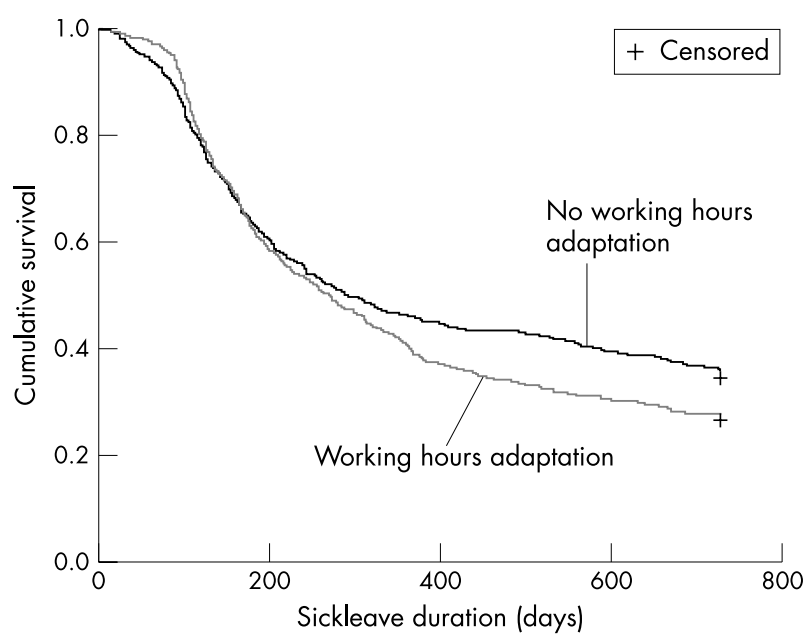

Figure 4 Survival curves of absence from work for workers with and without adaptation of working hours. 
to workers sicklisted for 4-6 weeks because of LBP compared to 3-4 months in our study. Our finding that some ergonomic interventions were successful for workers with more than 200 days sickleave could be explained by the late timing of these interventions. Another explanation for this phenomenon is that in the first period of sickleave the vast majority of the patients will return to work as a result of the natural course of recovery after an episode of low back pain. ${ }^{22}$ Return-to-work might occur in these patients, irrespective of an application of an ergonomic intervention. However, for patients with sickleave of more than 200 days, the chance of return-to-work becomes very low and an ergonomic intervention, such as adaptation of job tasks or hours adaptation, might support or initiate return-to-work.

\section{Meaning of this study}

Our results suggest that ergonomic interventions are effective on long lasting return-to-work for workers sicklisted for 3-4 months due to LBP. Although most of the ergonomic interventions reveal effects in the long term, the impact in the prevention of occupational disability due to LBP and in the reduction of costs to the society may be important. The principal meaning of this study is that interventions for the occupational rehabilitation of workers sicklisted due to LBP should include ergonomic interventions.

It will be difficult to study the effectiveness of ergonomic interventions on return-to-work in RCTs, because, as this study shows, the occurrence of these interventions is high in usual care. However, the effectiveness of ergonomic interventions on return-to-work should be shown in future RCTs to rule out possible bias and confounding.

\section{ACKNOWLEDGEMENTS}

We thank AS/tri Research and Consultancy group for the scientific coordination of this multinational study and all participants in the Work Incapacity and Reintegration project for their contributions to this study. We thank the International Social Security Association (ISSA) for initiating this study. We thank the IEA Data Processing Centre, Hamburg, Germany for the data. Body@Work, Research Centre Physical Activity, Work and Health is part of the Institute for Research in Extramural Medicine and is a joint initiative of TNO Work and Employment, the VU Medical Centre, and TNO Prevention and Health.

BC contributed to the conception and design of this study. JRA, BC, AJvdB, DLK, HCWV, and WVM contributed to the analysis and writing up of this study. JRA, BC, and WvM will act as guarantors of this study.

\section{Authors' affiliations}

J R Anema, Body@Work, Research Centre Physical Activity, Work and Health, TNO-VU University Medical Centre, Netherlands

B Cuelenaere, AS/tri Research and Consultancy Group, Leiden, Netherlands

A J van der Beek, W van Mechelen, Department of Social Medicine and Institute for Research in Extramural Medicine, VU University Medical Centre, Amsterdam, Netherlands

H C W de Vet, Institute for Research in Extramural Medicine, VU University Medical Centre, Amsterdam, Netherlands
D L Knol, Department of Clinical Epidemiology and Biostatistics and, Institute for Research in Extramural Medicine, VU University Medical Centre, Amsterdam, Netherlands

Funding: Social Security Supervisory Board, the Netherlands Ministry of Social Affairs and Employment and the Netherlands Ministry of Health, Welfare and Sports, with a grant from the General Disability Funds.

Competing interests: None declared

\section{REFERENCES}

1 Hoogendoorn WE, Bongers PM, de Vet HC, et al. High physical work load and low job satisfaction increase the risk of sickness absence due to low back pain: results of a prospective cohort study. Occup Environ Med 2002;59:323-8.

2 Shaw WS, Pransky G, Fitzgerald TE. Early prognosis for low back disability: intervention strategies for health care providers. Disabil Rehabil 2001;23:815-28.

3 Frymoyer JW. Predicting disability from low back pain. Clin Orthop 1992;279:101-9.

4 Gallagher RM, Rauh V, Haugh LD, et al. Determinants of return-to-work among low back pain patients. Pain 1989;39:55-67.

5 Hazard RG, Haugh LD, Reid S, et al. Early prediction of chronic disability after occupational low back injury. Spine 1996;21:945-51.

6 Beissner KL, Saunders RL, McManis BG. Factors related to successful work hardening outcomes. Phys Ther 1996;76:1188-201.

7 Infante-Rivard C, Lortie M. Prognostic factors for return to work after a first compensated episode of back pain. Occup Environ Med 1996;53:488-94

8 van der Giezen AM, Bouter LM, Nijhuis FJ. Prediction of return-to-work of low back pain patients sicklisted for 3-4 months. Pain 2000;87:285-94.

9 van der Weide WE, Verbeek JH, Salle HJ, et al. Prognostic factors for chronic disability from acute low-back pain in occupational health care. Scand J Work Environ Health 1999;25:50-6.

10 Teasell RW, Bombardier C. Employment-related factors in chronic pain and chronic pain disability. Clin J Pain 2001;17(suppl 4):S39-45.

11 Staal JB, Hlobil H, van Tulder MW, et al. Return-to-work interventions for low back pain: a descriptive review of contents and concepts of working mechanisms. Sports Med 2002;32:251-67.

12 Elders LA, van der Beek AJ, Burdorf A. Return to work after sickness absence due to back disorders - a systematic review on intervention strategies. Int Arch Occup Environ Health 2000;73:339-48.

13 Krause N, Dasinger LK, Neuhauser F. Modified work and return to work: a review of the literature. J Occup Rehabil 1998;8:113-39.

14 Loisel P, Abenhaim L, Durand $P$, et al. A population-based, randomized clinical trial on back pain management. Spine 1997;22:2911-18.

15 Haldorsen EM, Kronholm K, Skoven JS, et al. Multimodal cognitive behavioral treatment of patients sicklisted for musculoskeletal pain. A randomized controlled study. Scand J Rheumatol 1998;27:16-25.

16 Rossignol M, Abenhaim L, Seguin P, ef al. Coordination of primary health care for back pain. A randomized controlled trial. Spine 2000;25:251-9.

17 Bloch FS, Prins R. Who returns to work and why? A six country study on work incapacity and reintegration. International Social Security Series, Vol. 5. New Brunswick (USA) and London (UK): International Social Security Series, 2001.

18 Hansson TH, Hansson EK. The effects of common medical interventions on pain, back function, and work resumption in patients with chronic low back pain: a prospective 2 -year cohort study in six countries. Spine 2000;25:3055-64.

19 Anema JR, van der Giezen AM, Buijs PC, et al. Ineffective disability management of doctors is an obstacle for return-to-work. A cohort study on low back pain patients sicklisted for 3-4 months. Occup Environ Med 2002;59:729-33.

20 Wolf $\mathrm{J}$, Cuelenaere B. Technical guide to the international database $\mathrm{T} 1$ to $\mathrm{T} 3$. Study on Work Incapacity and Reintegration (WIR) project. Hamburg, Leiden, Geneva: International Social Security Association Research Programme, 2000.

21 Fleten N, Johnsen R, Ostrem BS. [Sick-listed persons think job adjustments might reduce sick-leave]. Tidsskr Nor Laegeforen 1999;1 19:3730-4.

22 Frank JW, Brooker AS, DeMaio SE, et al. Disability resulting from occupational low back pain. Part II: What do we know about secondary prevention? A review of the scientific evidence on prevention after disability begins. Spine 1996;21:2918-29. 